University of Nebraska - Lincoln

DigitalCommons@University of Nebraska - Lincoln

7-2011

\title{
"The Love Games People Play" Survey: Using Research Methods to Examine Gendered Scripts and Stereotypes
}

Kristen Lucas

University of Nebraska-Lincoln, kristen.lucas@louisville.edu

Follow this and additional works at: https://digitalcommons.unl.edu/commstudiespapers

Part of the Communication Commons

Lucas, Kristen, "'The Love Games People Play" Survey: Using Research Methods to Examine Gendered Scripts and Stereotypes" (2011). Papers in Communication Studies. 18.

https://digitalcommons.unl.edu/commstudiespapers/18

This Article is brought to you for free and open access by the Communication Studies, Department of at DigitalCommons@University of Nebraska - Lincoln. It has been accepted for inclusion in Papers in Communication Studies by an authorized administrator of DigitalCommons@University of Nebraska - Lincoln. 


\title{
"The Love Games People Play" Survey: Using Research Methods to Examine Gendered Scripts and Stereotypes
}

\author{
Kristen Lucas \\ University of Nebraska-Lincoln \\ Lincoln, NE 68588, USA \\ Email klucas3@unl.edu
}

Courses: Interpersonal Communication, Gender Communication, Research Methods

Objectives: - To test gendered scripts and stereotypes associated with romantic relationships.

- To use research methods to answer an intrinsically interesting research question.

\section{Rationale}

Every day we are bombarded with information about romantic relationships. Magazine articles offer how-to advice on flirting, dating, and fixing relationship problems. Advertisements - from billboards to radio commercials to email marketing campaigns - feature products that promise to help people attract a special someone. Television and movie actors portray characters who fall in and out of love. And a slew of self-proclaimed gender experts boldly proffer communication advice such as "Don't ask where he is or what he's doing" (Argov, 2009) and "Make it your mission to talk to as many women as possible" (Edwards, 2008). Whether these outlets create the rules for society or simply reflect them, there is a complex web of gendered scripts and stereotypes that define appropriately feminine and masculine dating behavior (Metts, 2006; Wood, 2011).

The purpose of this activity is for students to examine systematically gendered scripts and stereotypes about romantic relationships. As a secondary purpose, the activity demonstrates the value of communication research in seeking dependable answers to important questions. 


\section{Activity}

This activity is designed to cover two class periods. The first class is used to set up the study and the second class is used to present and discuss the results. The activity requires additional prep work between the designated class periods. The first and second classes do not necessarily have to be held over consecutive class periods. The classes may be scheduled a week apart (or slightly more, if necessary) to allow time to collect and analyze the data.

\section{First Class}

Begin this activity by presenting selected media portrayals of gendered scripts for dating. In addition to highlighting advice from self-help books, you also may play video clips from popular movies and TV shows that explicitly state dating rules (many are available on YouTube.com; see Appendix). For example, in the movie Swingers, there is a scene where one of the male characters obtains a woman's phone number and his friends explain to him that there are rules about calling too soon. In a later scene, he breaks the rule by calling immediately and is told by the woman that she does not want to talk to him again. Ask students to share insights from recent movies, television shows, and their personal and vicarious experiences. Once examples have been shared, explicitly state the take-away point: For better or for worse, there are rules about the ways that men and women should behave in heterosexual romantic relationships. Then explain to the class that you are going to walk them through a communication research study to explore the prevalence of such cultural scripts and stereotypes.

Next, ask students to get into small groups. Give the groups between five and ten minutes to generate lists of dating rules and assumptions. When students have finished, have them share their answers in round-robin fashion. Appoint a student to write down the complete list and give it to you after class (preferably he or she should email it). Emphasize that because the point is to get the most complete list of rules possible, they should share all their ideas, even ones they think are silly or ineffective. You also may probe students with questions to trigger additional ideas ("How about asking someone out on a first date?", "Who should propose?").

When students have exhausted all their ideas, explain to them that they just participated in a qualitative data collection procedure and that the next step in the research process is to convert those qualitative data into a survey that can be used to test the prevalence of the rules. Inform students that you will soon send them a link to an online survey. Encourage students to share the link with others, especially if you teach a smaller course. Also, if you do not have an equal number of men and women in the class, ask students to have a friend of the opposite sex complete the survey to keep the sex distribution of respondents relatively balanced. 


\section{Between-Class Preparation}

After class, convert the list of rules into a survey that can be administered to students. This part of the preparation should take between one and two hours. One option is to use Survey Monkey (http:/ / www.surveymonkey.com). This service is free for up to 10 questions and 100 responses, which should be plenty for this activity. Four basic questions are recommended: (1) What is your sex [male or female]; (2) Indicate the degree to which you think the following gendered assumptions are true [seven-point Likert scale from 1 = "strongly disagree" to $7=$ "strongly agree"; insert the studentgenerated list of gendered assumptions]; (3) Indicate the degree to which you think the following gender rules reflect general beliefs about dating [seven-point Likert scale from 1 = "strongly disagree" to 7 = "strongly agree"; insert the list of gender role rules, clearly identifying if the rule is for men or women]; and (4) Indicate the degree to which you think the following rules are effective and/or should be followed [ 1 = "very ineffective/should never be followed" to 7 = "very effective/ should always be followed"; insert the list of gender role rules again). When the survey is completed, email the survey link to the class and provide a deadline for completing the survey (48 hours is recommended).

Once the data collection is complete, the next step is to analyze the data. This part of the preparation can take several hours, depending on how many hypotheses are tested. At a minimum, identify the most widely believed gendered assumptions/ rules (report the items with the highest overall means), and what, if any, sex differences exist in the rules (run independent sample $t$-tests and report items with a statistically significant difference between men and women). Prepare a PowerPoint presentation that summarizes the results.

\section{Second Class}

Conclude this activity by sharing the results with students and leading a discussion about gendered scripts and stereotypes. To keep with the theme of this activity being a research project, an effective way of presenting the results is to follow a formal research format. Begin by briefly recapping the rationale for the study and some of the highlights from the "literature" (i.e., the movie clips). Second, pose the guiding research question: How prevalent are gendered rules of romantic relationships? Third, provide an overview of the method.

Phase I was an in-class qualitative data collection. For Phase I results, present a brief thematic analysis. Rules typically can be classified into a typology of Gender Assumptions (beliefs about the romantic motivations of each sex; "women are looking for commitment"), Gender Roles Rules (beliefs about what behaviors each sex should engage in; "men should pay for the first date"), Physical/Sexual Contact Rules (beliefs about what constitutes proper physical/sexual dating behavior; "men should make the first sexual move"), and Manipulation/"Game" Rules (communicative strategies employed to win the dating game, "You should wait two or three days to call"). Present themes and provide exemplars to illustrate each. 
Phase II was a quantitative survey. Here, present the descriptive data on the participants in formal terms (e.g., "Students from a large, Midwestern university," " $n$ $=78^{\prime \prime}$ ). Begin these results with the research question "What rules are most strongly believed?" Provide a list of the top five rules based on their mean score (report the mean and standard deviation for each rule). Then, address the question "Are there differences between men and women?" Highlight the rules with statistically significant differences, including the $t$-statistics, $p$-values, and effect sizes. Present results of any other analyses that may be of interest.

Finally, open the floor to class discussion. Some questions to guide the discussion include: How do you interpret these results? What have you learned about "rules" for dating? What results surprised you? In what ways did systematic communication research do a better job of presenting differences and/or similarities as compared to the stereotypes you see in the media? What are the limitations of this research? What is culturally unique about your class that may not reflect the population as a whole (i.e., sample bias)? What would you want to know next? How will you behave differently now that you have this information?

\section{Debriefing}

When the activity is complete, debrief the class by explaining that gendered scripts and stereotypes often are accepted as indisputable truths. When these "rules" are followed, they are further reinforced and naturalized regardless of whether there is a sound basis for their existence. For example, in one class the old adage that "men love the chase" did not hold up as well as expected. Statistically significant results revealed that women strongly believed this stereotype (and many admitted modifying their behaviors accordingly, for example, by playing hard to get). Yet, men were neutral toward this gendered assumption and not a single male respondent strongly agreed with the statement. When students can see that these scripts and stereotypes are not supported by research (even if not particularly rigorous), it may encourage them to be more critical of other gendered messages they are receiving.

The debriefing also is an excellent time to discuss heteronormativity and other cultural biases reflected in this project. You may expose some of these biases by asking questions such as: How might the rules be different for gay couples? Where do they learn about dating expectations? What about older adults? Senior citizens? People of different religions? Different races, ethnicities, or nationalities? More importantly, why is it problematic to assume that these rules are universal in our diverse society? How might communication researchers address cultural diversity in future studies about romantic relationships?

\section{Variations}

This activity can be modified for different needs. For a methods class, students could be more involved in the research process: finding scholarly sources for a liter- 
ature review, doing a thematic analysis of qualitative data, constructing and administering online surveys, statistically testing their own research questions and hypotheses, and writing a short research report. If time is of the essence, this activity can be shortened by doing the first day activity, having students complete the online survey, and then providing a brief (10-minute) summary of the results in a later class period. Additionally, the content of the survey can be modified to include concepts related to different courses (e.g., intercultural, political, friendship, or family communication).

\section{Appraisal}

This activity has been extremely popular. Students have been eager to complete the survey. (In fact, this activity blossomed out of a student asking, "Why couldn't we do a survey on this?") Class discussion has been engaged, passionate, and interesting. The activity also provides the added benefit of reinforcing what communication majors learned in their research methods class. For students who did not take methods courses - especially for students taking the course as a general education requirement-it served the purpose of portraying the communication discipline as a serious academic discipline.

In conclusion, as romantic relationships are a central interest for college students, they are highly motivated to seek information and insight to guide them. Instead of leaving it to movie stars and magazines, this activity provides an insightful and more credible alternative for getting the information they desire.

\section{References and Suggested Readings}

Argov, S. (2009). Why men love bitches: From doormat to dreamgirl - A woman's guide to holding her own in a relationship. Avon, MA: Adams Media.

Edwards, L. (2008). Secrets of the A game: How to meet and attract women anywhere, anyplace, anytime. Los Angeles, CA: Sweetleaf.

Metts, S. (2006). Gendered communication in dating relationships. In B. J. Dow \& J. T. Wood (Eds.), Sage handbook of gender and communication (pp. 25-40). Thousand Oaks, CA: Sage.

Wood, J. T. (2011). Gendered lives: Communication, gender, and culture (9th ed.). Belmont, CA: Thomson Wadsworth.

\section{Appendix A: Sample Movies and TV Shows}

- Friends (episode where Monica proposes to Chandler)

- He's Just Not That Into You

- Hitch

- How I Met Your Mother

- How to Lose a Guy in 10 Days

- Sex in the City

- Swingers (Mikey's phone call)

- The Bachelor and The Bachelorette 